\title{
Discussion on Bilingual Teaching in Biomedical Engineering
}

\author{
ZHENG Yilin ${ }^{1, a}$, WANG Yu ${ }^{2, b}$ and LI Zheng ${ }^{3, c}$ \\ ${ }^{1,2,3} \mathrm{HeBei}$ University of Science and Technology, School of Electric Engineering \\ Shijiazhuang, Hebei Province, China \\ asuezyl@163.com, bwangyu0228@live.cn, ' Izhfgd@163.com
}

Keywords: bilingual teaching; biomedical engineering; foreign original textbook

\begin{abstract}
This article discussed the rationality of the bilingual teaching in biomedical engineering, explored the possibility of employing foreign original textbook and utilization of multimedia technology to improve the quality of bilingual teaching, proposed a target on student's individualization, emphasized the people-oriented principle in teaching process, concluded beneficial enlightenment of the bilingual teaching in biomedical engineering.
\end{abstract}

\section{Introduction}

English as the common language in the world today, conveys an extremely widespread information in the field of science and technology. Bilingual teaching in biomedical engineering has important significance. Not only it improves students' ability to understand the latest scientific and technological achievements in the global biomedical domain, but also accelerates the pace of adapting our high-level education in colleges and universities to international standards. This article is in the hope of providing references based on our personal practices to steady development of bilingual teaching by discussing our accumulated experiences and solutions to difficulties we experienced.

\section{Definition of Bilingual Teaching}

Bilingual teaching is defined as to employ two different languages as the medium in teaching activities. Instructors and students can interact with each other using both Chinese and foreign language frequently in communication and teaching process on discipline knowledge, and ultimately to achieve the goal that both instructors and students are able to utilize two thinking modes in language as necessary in disciplinary learning and researching.

\section{Rationality of Bilingual Teaching in Biomedical Engineering}

Whether or not bilingual teaching can be used in a course, is mainly determined by the course's disciplinary characteristics. It is difficult to carry out bilingual teaching in humanities and social sciences due to the fact that more native culture is being involved. But on the other hand, some disciplines like mathematics, physics, chemical, biotechnology, computer, and etc. have more international commonality. Their way of expression, terminology comprehension and interpretation are relatively consistent across different languages and culture. So the general trend today around the world is that they become the first choices of curriculums when bilingual teaching is implemented. Biomedical engineering is one of them. It combines disciplines across science, engineering, medicine and product of infiltration with variety of engineering technology into biomedical field; it is appropriate and necessary to use bilingual teaching [1].

Through employing English in teaching process, students can learn appropriate expertise; while at the same time it may improve their English proficiency and overall quality. This exactly meets the talent requirements of rapid developing export-oriented economy, and is also an important aspect of our traditional teaching mode reform. Therefore, objectives of bilingual teaching were set according to the actual situation, and basic medicine course was opened on a trial in biomedical engineering. 
The original edition of "Understanding Human Anatomy and Physiology" was applied as textbook, lectures were instructed both in English and Chinese, which taught in English is not less than 50\%, and courseware, blackboard writing, as well as exam papers were all in English.

\section{Problems in Bilingual Teaching}

A. Impact of students' foreign language proficiency to bilingual teaching

The difference of each student's language level has important implication to bilingual teaching. The students with good basis of foreign language get the knowledge faster. The others are hard to understand the keywords of professional knowledge, ever the teachers' speaking. Therefore, the bilingual education has higher quality requirements to the students' skill of foreign languages.

B. Impact of teachers' foreign language proficiency to bilingual education

Bilingual teaching is not only a challenge to the students to learn professional knowledge, but also a problem which placed in front of the teachers. Teachers should be proficient professional knowledge, and also can be fluent in a foreign language expertise in expression. And sometimes even to teach students to think in English thinking ways. In particular, the level of spoken language teachers directly affects the teaching effect.

C. Bilingual textbook for bilingual teaching

The quality of faculty and students are objective factors which affect bilingual teaching. But the choosing of bilingual textbooks have subjective effects on bilingual teaching. Currently, there are two kinds of bilingual materials. One is the foreign original textbook. The other is the foreign language material which is translated by domestic scholars. Different people harbor different views about the two kinds of materials. Some people think that the first is better than the second. On the ground that foreign original textbooks include not only the specific expression, but also the thinking ways by English. But it is difficult to the teaching. While, others think that the translation is easier to understand.

\section{Discussion on Teaching Methods}

For the current problems in bilingual teaching, this paper conduce a preliminary exploration of bilingual teaching methods to improve bilingual teaching effectiveness. Then the teachers and students can improve themselves in the teaching process.

A. Progressive teaching methods

The actual capacity of students must be taken into consideration when carrying out bilingual teaching. So we adopted a step-by-step approach by reducing English proportion at the beginning of class to enable students adapt gradually. Firstly, we start from $10 \%-20 \%$ before students have mastered special terminology, then we gradually increase the proportion of English in teaching according to the students' acceptance, and eventually make content taught in English reach 50\% of curriculum. And there is a concept must be clear: implementation of bilingual teaching does not mean that the more English, the better. Because the purpose of bilingual education is not to teach students English, but to impart professional knowledge in two languages and thinking models, not to make the secondary supersedes the primary [2].

B. Employ multimedia technology to improve quality of bilingual teaching

Employing modern information technology to improve education is the newer and higher requirement in the 21st century put forward by the Ministry of Education for higher education, among which, multimedia technology can even more demonstrate its superiority in bilingual teaching. In a bilingual instruction, using slides and other multimedia means to enhance teaching process, not only will it increases information capacity in class, but also provides aural and visual information by sound and projection screen, like presenting exquisite microscopic pictures of biological structure, colorful vivid flash animation and original English videos. In this way, abstract concepts in disciplines become concrete and knowledge appears visible. Thus, it is conducive to teacher's interpretation in English, while enriching teaching contents and also making teaching process more vivid by the 
boring at the same time. Additionally, this innovative manner will be able to stimulate students' interest in learning, enhance the effect of teaching, and cause students to grasp the curriculum well with key point and difficulty. This is the call of the era, as well as requirements of quality education [3]

C. Selection of appropriate foreign original edition textbooks

Textbooks are carriers of knowledge. Lacking suitable teaching materials, teaching process will like water without a source, a tree without roots. For bilingual teaching curricula, textbooks selected appropriately or not have a direct impact on teaching effectiveness. From the content point of view, abroad excellent original textbooks are considered to be worldwide excellent teaching materials in regard of its technicality, system rationality and updates timeliness, and they are superior to domestic textbooks. From the language point of view, only foreign experts can use their native language to write textbooks fluently, which not only includes scientific rational thought, but also contains essence of western language.

Therefore, the adoption of English original textbooks may enable students to have the opportunity to read teaching materials written by world first-class experts, and to learn authentic English, while also can guarantee timely updates of the contents and up-to-date international practice[2]. When selecting appropriate abroad materials, in addition to focusing on principles of advancement, technicality and vulnerable acceptance, it is also important to consider its compilation idea, content depth and coverage, chart usage, whether or not it contains cutting edge theory in the discipline and is in line with international trend of development, and the level of difficulty of it's language and etc [4].

\section{Biomedical Engineering Bilingual Teaching Case}

Through the demonstration of biomedical engineering case of bilingual teaching, we could have a deeply understanding of bilingual teaching. Demonstration case is shown as follows.

A. Character and purpose of the course

Character: This course is an integrated overview for the "Medical Biological Engineering" specialty and is lectured in English.

Objective: Through this course of study, to enable students a general understanding of the development of "Medical Biological Engineering”, interdisciplinary content, the basis characteristics as well as professional curriculum overview.

B. Main content of teaching

We use the step-by-step approach to help the students understand the professional knowledge what is shown in Fig.1.

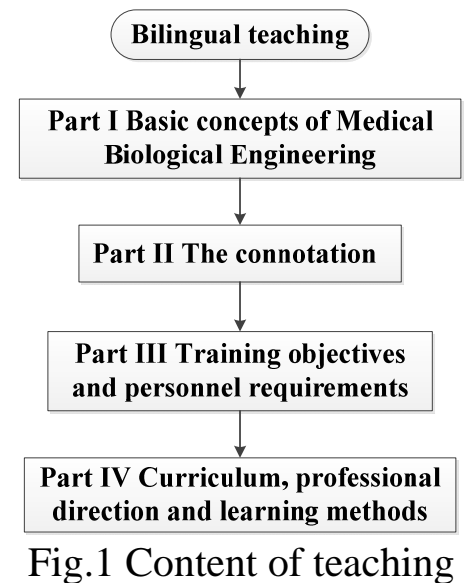

Part 1: Basic concepts of Medical Biological Engineering

Basic requirements: The students should master the object, contents, features of Medical Biological Engineering, and its roles, and status in the national economy, understand the development process of Medical Biological Engineering, the electrical engineering technology on productivity development and social progress in promoting.

Part 2: The connotation 
Basic requirements: To master electrical engineering research focus and discipline content, understanding electrical engineering and control theory.

Part 3: Training objectives and personnel requirements

Basic requirements: The students should master the professional categories, electrical engineering training objectives and personnel quality requirements.

Part 4: Curriculum, professional direction and learning methods

Basic requirements: The students should master the ways of professional learning, the relationship between pre-professional courses and basic courses, specialized courses, understanding the importance of basic courses and professional orientation, learning the focus and difficulty.

C. Course hours distribution

There are Total 8 class hours. The distribution of course hours is shown in Tab.1.

\begin{tabular}{|c|c|}
\hline content & hours \\
\hline Basic concepts of Electrical Engineering and Automation & 2 \\
\hline The connotation & 2 \\
\hline Training objectives and personnel requirements & 2 \\
\hline Curriculum, professional direction and learning methods & 2 \\
\hline Total & 2 \\
\hline
\end{tabular}

Tab 1 Distribution of course hours

\section{VI . Conclusions}

In conclusion, bilingual teaching in open class suggests a new teaching approach for students in learning expertise along with foreign language on one hand while on the other, instructors themselves can also benefit from it greatly when they read original materials or literature in English. Beside understanding latest theory and technology from abroad on biological medical and dynamic and progress on the forefront of development of the discipline, they can also be prompted to learn English unceasingly and thus to improve their professional level. In this sense, bilingual teaching may benefit both teachers and students, and enable them to benefit from it mutually [5].

\section{References}

[1] HE Quanguo; YANG Yulin; YANG Yun. Practice and Discussion of Bilingual Teaching in Biomedical Engineering [J]. Journal of Peking University, 2007(5):224-225

[2] LIU Xiaoci; ZHANG Fuheng. Discussion on the Core of Bilingual Teaching is Foreign Teaching Materials [J]. Journal of Peking University, 2007(5):270-272

[3] LI Hongbing. Discussion on bilingual teaching model [J]. Journal of technology college education, 2002(3):111-112

[4] CUI Yan, Kong Qingxue. Exploration on bilingual teaching in courses of bioengineering [J]. Journal of tianjin agricultural university, 2012(1)59-61

[5] LIU Jingwen, CAO Minjie, ZHU Yanbing, CAI Qiufeng, LI Lijun, DU Cuihong, QIU Xiaoyan. Innovation and practice of bilingual teaching in bioengineering specialty courses [J]. Journal of Jimei University, 2011(4):110-112 